\title{
Role of oxygen content in the structural and the superconducting properties of high temperature superconducting $\mathrm{ErBa}_{2} \mathrm{Cu}_{3} \mathrm{O}_{y}$
}

\author{
G K BICHILE ${ }^{\dagger}$, D G KUBERKAR, A K RAJARAJAN*, \\ S S SHAH, L C GUPTA* and R VIJAYARAGHAVAN* \\ Department of Physics, Marathwada University, Aurangabad 431004 , India \\ * Tata Institute of Fundamental Research, Bombay 400005 , India.
}

\begin{abstract}
Samples of high temperature superconducting system $\mathrm{ErBa}_{2} \mathrm{Cu}_{3} \mathrm{O}_{y}$ prepared by the standard ceramic technique were found to have single phase. To vary the oxygen content in the samples, the mother compound was reduced by vacuum-annealing at different temperatures for a fixed period. The oxygen content was measured by gravimetric and iodometric titration procedures. The structural changes induced due to the variations in the oxygen content were studied by $\mathrm{X}$-ray methods.
\end{abstract}

Keywords. Oxygen stoichiometry; structural features; transition temperature.

\section{Introduction}

It has been generally observed that the superconducting transition temperature $T_{c}$, the transition width $\Delta T_{c}$ and the extent of orthorhombic distortion in the ceramic superconductors depend markedly on the overall oxygen stoichiometry and on the ordering of oxygen atoms and oxygen vacancies on the available sites (Cava et al 1988). After the discovery of high temperature superconducting $\mathrm{YBa}_{2} \mathrm{Cu}_{3} \mathrm{O}_{y}$, attempts have been made to understand the origin and mechanism of high $T_{c}$ superconductivity and to search for new high $T_{c}$ materials. It was reported that ordering plays a crucial role in high temperature superconductivity (Siegrist et al 1987). The role of oxygen in determining the structural symmetry and its correlation with $T_{c}$ has been reported earlier (Jorgensen et al 1987) but the specific role and relative importance of the $\mathrm{Cu}_{2}-\mathrm{O}$ planes and the $\mathrm{Cu}-\mathrm{O}$ chains are more controversial. The asymmetric distribution of oxygen leads to an orthorhombic distortion $(b-a)$. The difference between $b$ and $a$ is a measure of the degree of ordering and the larger $(b-a)$ values the higher is the degree of ordering. It is not obvious, however, that for the same values of oxygen content, the same degree of ordering occurs.

Experimental evidence indicates that the arrangement of oxygen vacancies depend on the precise control over the important processing parameters, namely, the final annealing temperature, oxygen partial pressure, annealing atmosphere and the quenching rate etc (Chen et al 1988). To our knowledge there are only a few investigations on the oxygen vacancy phases of $\mathrm{REBa}_{2} \mathrm{Cu}_{3} \mathrm{O}_{y}$ systems ( $\mathrm{RE}$ is any rare earth element). It is important to know whether the physical and structural properties of the rare earth-based 1-2-3 systems have a dependence on oxygen stoichiometry in relation to oxygen content and ordering, similar to that observed for the $\mathrm{YBa}_{2} \mathrm{Cu}_{3} \mathrm{O}_{y}$ system.

With this in view and to study the relative role of oxygen content and ordering on the superconducting behaviour of these HTSC systems it was considered desirable to study the superconducting properties as a function of oxygen stoichiometry and 
the associated structural changes. In this paper we report the results of our study on the effect of the gradual changes in the oxygen content of $\mathrm{ErBa}_{2} \mathrm{Cu}_{3} \mathrm{O}_{y}$ system on its structural changes, the transport properties and the superconducting transition temperature.

\section{Experimental}

\subsection{Sample preparation}

The $\mathrm{ErBa}_{2} \mathrm{Cu}_{3} \mathrm{O}_{y}$ sample was originally prepared by the standard solid-state reaction of $\mathrm{Er}_{2} \mathrm{O}_{3}\left(99.9 \%\right.$, Aldrich), $\mathrm{CuO}\left(99.9 \%\right.$, FLUKA) and $\mathrm{BaCO}_{3}(99.5 \%$, Thomas Baker) powders. Stoichiometric quantities of these powders were thoroughly mixed, ground and calcined at $920^{\circ} \mathrm{C}$ for $24 \mathrm{~h}$ and reground and reheated till a homogeneous and single-phase sample was obtained. The powder was then pelletized and the pellets sintered at $920^{\circ} \mathrm{C}$ for $24 \mathrm{~h}$.

To obtain a fully oxygenated sample ( $y$ close to 7 ), the sintered pellets were annealed in flowing oxygen at $450^{\circ} \mathrm{C}$ for $36 \mathrm{~h}$ and subsequently cooled slowly to room temperature at $1^{\circ} \mathrm{C} \mathrm{min}^{-1}$.

The partially deoxygenated samples were obtained by annealing in vacuum $\left(<10^{-3}\right.$ torr) at various temperatures for a fixed period.

\subsection{Characterization}

The samples were characterized using Siemens X-ray diffractometer and $\mathrm{CuK}_{\alpha}$ radiation. XRD studies revealed that the samples are single-phase and homogeneous. The stoichiometric composition was checked by EDAX analysis using a JEOL scanning electron microscope. The oxygen content of the deoxygenated samples was derived from the known starting composition and the measured weight change in the sample. This value was checked by performing iodometric titrations (Nazzal et al 1988) for 3--5 times on the small portion of each sample. The oxygen content thus determined is accurate to within \pm 0.02 oxygen per formula unit.

The superconducting transition temperature $T_{c}$ was determined by resistive and inductive methods using the standard d.c. four-probe technique and the mutual inductance method respectively for all the samples with known oxygen content.

\section{Results and discussion}

X-ray powder diffraction data of the original sample were analysed using a least square program. The values of the refined unit cell parameters and the resistive transition temperature are in good agreement with the reported values (Takagi et al 1987). The oxygen content in the samples was varied using the vacuum annealing method (Cava et al 1988).

Table 1 gives the oxygen content values determined by using iodometric and gravimetric techniques and the corresponding values of the transition temperature $T_{c}$ for different deoxygenated samples determined by resistivity measurements. 
Table 1. Transition temperature $T_{c}$ and transition width $\Delta T_{c}$ for different values of oxygen content of $\mathrm{ErBa}_{2} \mathrm{Cu}_{3} \mathrm{O}_{y}$

\begin{tabular}{lcccc}
\hline Sample & \multicolumn{2}{c}{$\begin{array}{c}\text { Oxygen concent }(y) \\
\text { Gravimety }\end{array}$} & \multicolumn{2}{c}{$\begin{array}{c}T_{c}(\mathrm{~K}) \Delta T_{c}(\mathrm{~K}) \\
\text { Resistive }\end{array}$} \\
\hline $059 \mathrm{M}$ & 6.95 & 6.94 & 88 & 3 \\
059 vac $330^{\circ} \mathrm{C}$ & 6.81 & 6.81 & 86 & 3 \\
059 vac $360^{\circ} \mathrm{C}$ & 6.78 & 6.79 & 82 & 4 \\
059 vac $400^{\circ} \mathrm{C}$ & 6.65 & 6.63 & 55 & 6 \\
059 vac $450^{\circ} \mathrm{C}$ & 6.54 & 6.54 & 46 & - \\
059 vac $500^{\circ} \mathrm{C}$ & 6.20 & 6.23 & - & - \\
059 vac $600^{\circ} \mathrm{C}$ & 6.04 & 6.02 & - & - \\
059 vac $650^{\circ} \mathrm{C}$ & 6.02 & 6.05 & - & 8 \\
\hline
\end{tabular}

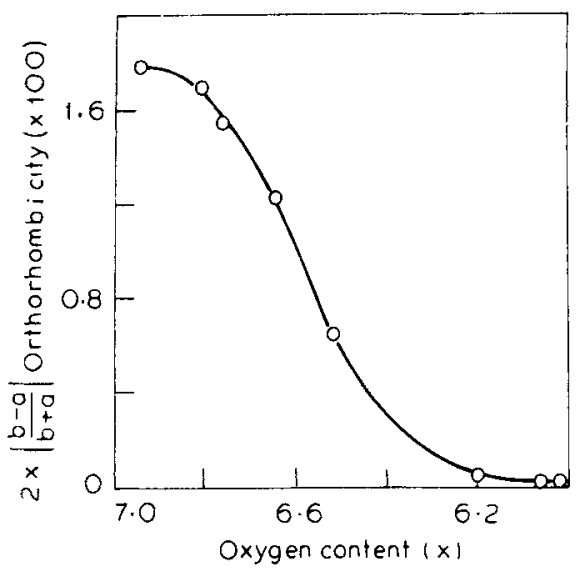

Figure 1. Variation in orthorhombicity parameter with the oxygen content in $\mathrm{ErBa}_{2} \mathrm{Cu}_{3} \mathrm{O}_{y}$.

Figure 1 depicts the variation in the orthorhombicity parameter (defined as 2 . $b-a / b+a)$ with the oxygen content in the $\mathrm{ErBa}_{2} \mathrm{Cu}_{3} \mathrm{O}_{y}$ system. The decrease in oxygen concentration is accompanied by a gradual change in the orthorhombicity value up to $6 \cdot 25$, below which the sample shows a tetragonal behaviour.

The present results indicate that the rate of evolution of oxygen is slow up to $400^{\circ} \mathrm{C}$ and thereafter the desorption process is fast resulting in a fully tetragonal non-superconducting phase.

\section{References}

Cava R J, Batlogg B, Ramirez A P, Werder D, Chen C H, Rietman E A and Zahurak S M 1988 Mater. Res. Soc. Symp. Proc. 9919

Chen T M, Bringley J F, Averill B A, Wong K M and Poon S J 1988 in Superconductivity:Synthesis, Properties and Processing (ed.) W E Hatfield (New York: Marcel Dekker) Chap. 19

Jorgensen J D et al 1987 Phys. Rev. B36 3608

Nazzal A I, Lee A Y, Englar E M, Jacowitz R D, Tokura Y and Torrance J B 1988 Physica C153 1367

Siegrist T, Sunshine S, Murphy D W, Cava R J and Zahurak S M 1987 Phys. Rev. B35 7137

Takagi H, Uchida S, Sato H, Ishii H, Kishio K, Kitazawa K, Fueki K and Tanaka S 1987 Jpn. J. Appl. Phys. 26 L601 